\title{
INICIACIÓN SEXUAL, PRÁCTICAS SEXUALES Y PREVENCIÓN AL VIH/SIDA EN JÓVENES DE SECTORES POPULARES: UN ANÁLLISIS ANTROPOLÓGICO DE GÉNERO'
}

\section{Mabel Grimberg \\ Universidad de Buenos Aires - Argentina}

Resumen: Este estudio es parte de la línea Género y Prevención de un Programa de Investigación sobre VIH/SIDA. Desde un enfoque político y relacional esta línea indaga en las relaciones, los roles y las identidades de género en el contexto de la vida cotidiana. Este trabajo analiza la iniciación sexual y algunas dimensiones de las prácticas sexuales de los jóvenes, incluyendo el cuidado sexual y su vinculación con las representaciones sobre el VIH/SIDA. Partimos de una visión crítica a las construcciones universalistas y naturalizadoras de la juventud y los jóvenes para focalizar en los modos cómo los jóvenes construyen sus prácticas y significaciones en el marco de sus contextos de interacción cotidianos. Proponemos que las posibilidades de prevención del VIH/SIDA dependen de un complejo en el que juegan las identidades y roles de género, las modalidades de las relaciones de poder y las asimetrías sociales en el acceso y el control de recursos materiales y simbólicos. Los datos provienen de un estudio etnográfico entre mujeres y varones jóvenes de 15 a 28 años de sectores populares, residentes en el cordón sur de la Ciudad de Buenos Aires.

Palabras clave: construcción social, género, jóvenes, sexualidad, VIH/SIDA.

Abstract: This study is part of a line of research on Gender and Prevention in a research program on the social construction of HIV/AIDS. From a political and relational approach this line researches in gender relations, roles and identities in the context of the daily life. This paper analyses sexual initiation and some dimensions of the sexual practices of young people, including their sexual care and social representations related with AIDS. From a critical point of departure to the universalist and naturalized constructions of youth and young people we focus on how practices and meanings are constructed by young people in particular contexts of interaction. We propose that self sexual care and prevention of HIV/AIDS depend on a complex in which play gender identities and roles of sort, the modalities of power relations and social asymmetries in the access and control of material and symbolic resources. The data come from an ethnographic study between low-income young

${ }^{1}$ Proyecto 1 F 149 UBACyT - PIP 03063 CONICET 
people, women and men from 15 to 28 years old in the southern area of the City of Buenos Aires.

Keywords: gender, HIV/AIDS, sexuality, social construction, young people.

El sostenido aumento de los casos de SIDA en Argentina ${ }^{2}$ y, como en otros países, su creciente visibilidad en asociación con poblaciones precarizadas, jóvenes, mujeres y usuarios de drogas inyectables ponen de manifiesto las condiciones de vulnerabilidad diferencial y las también diferenciales posibilidades de prevención cuando se entrecruzan contextos de precariedad y exclusión social con relaciones de género, de edad, étnicas, etc. Pero, sobre todo, pone en evidencia la carencia de políticas de salud que integren de manera sostenida prevención y asistencia en los marcos de políticas sociales más amplias.

En este contexto debe reconocerse que la problemática de la prevención del VIH trasciende los estrechos márgenes de la información, así como la realización de acciones técnico-operativas puntuales de distribución de preservativos y jeringas, aún cuando estos niveles de trabajo sean imprescindibles. Nuestro punto de partida es que esta problemática encierra complejos procesos que incluyen, además del conocimiento, el problema del reconocimiento y el desarrollo de estrategias de cuidado y autocuidado, que no deben pensarse en términos individuales. Por lo contrario, éstas solo pueden ser comprendidas en el marco más amplio del tejido de relaciones sociales y el contexto mas general de las trayectorias, las condiciones y modos de la vida social de los sujetos.

En esta perspectiva, debe reconocerse que las posibilidades de autocuidado y las prácticas de prevención del VIH/SIDA dependen de una trama compleja en la que juegan la organización de las identidades y roles de

\footnotetext{
${ }^{2}$ Los últimos reportes estiman en aproximadamente un total de 22,500 casos acumulados $(19,268)$ considerando las demoras en la notificación; el $76 \%$ de ellos concentrados en el área metropolitana (33\% en la ciudad de Buenos Aires, $43 \%$ en el Gran Buenos Aires). El 47\% de los casos corresponden a tramisión sexual $(26 \%$ por relaciones homosexual/bisexuales y $21 \%$ a través de relaciones heterosexuales sin protección); el $41 \%$ a usuarios de drogas por vía inyectable, mientras que el $6.8 \%$ a tramisión vertical. El $42 \%$ de quienes refieren haber contraido el VIH/SIDA por relaciones (hetero) sexuales no protegidas son menores de 30 años, entre los usuarios de drogas inyectables este porcentaje alcanza al $60 \%$. Si se considera las medianas y el tramo de edad que ocupa el segundo lugar, esta tendencia resulta claramente mas delineada entre las mujeres: 24 años en las mujeres frente a 28 años en los varones; mientras en las mujeres el segundo lugar lo ocupa el tramo de 13 a 24 años, en los hombres es el de 35 a 39 años (Boletín sobre el SIDA, junio, 2001).
}

Horizontes Antropológicos, Porto Alegre, ano 8, n. 17, p. 47-75, junho de 2002 
género, las modalidades de las relaciones de poder y las asimetrías sociales en el acceso y el control de recursos materiales y simbólicos (Campbell, 1999; Haour-Knipe, 1998). Parte de las tensiones de este juego se expresan en complicados mecanismos de presión/negociación y sobre todo, en el peso de los diferentes sentidos que unos y otras dan a las relaciones y prácticas sexuales y en este marco, al problema del cuidado (Amuchástegui, 1999).

Desde los noventa, el interés por las vinculaciones entre roles masculinos y procesos de salud-enfermedad ha ido creciendo a impulso de los problemas de salud reproductiva y prevención del VIH/SIDA. Desde diversas perspectivas, se ha señalado la relevancia de ciertas dimensiones de la construcción de las identidades masculinas y de las expectativas de desempeño de sus roles. Parte de esta producción ha mostrado que "el ser hombre" requiere una renovada confirmación personal y pública frente a pares (Gilmore, 1990; Kimmel, 1998); el valor conferido al "correr riesgos" (Fuller, 1997, 2001), el "uso riesgoso del propio cuerpo" (de Kiejer, 2001; Figueroa, 1998), el requerimiento de afirmación de identidad a través del ejercicio de poder sobre la mujer (Kaufman, 1997), etc. Algunos de estos desarrollos han centrado en las políticas de "masculinidades" desde enfoque relacionales de género (Messner, 1997) y en la problemática del cuerpo, articulando salud, cultura e identidad (Watson, 2000).

Un aspecto sustancial de la problemática de prevención al VIH/SIDA es una, todavía, predominante concepción universalista, ahistórica y naturalizadora de la juventud y los jóvenes como "problema social" tanto en los programas preventivos, como en gran parte de la bibliografía clínica, epidemiológica y de ciencias sociales en América Latina (Cardoso; Sampaio, 1995; Maddaleno; Munist; Serrano et al., 1995; Oliveira, 2000). En su mayoría estos abordajes expresan una visión estereotipada de la juventud como etapa "de riesgo" o "vulnerabilidad" en sí misma, y sobre todo una percepción negativa de la sexualidad y las prácticas sexuales de los jóvenes como "comportamientos de riesgo", en particular en asociación con el "embarazo precoz" y las enfermedades de trasmisión sexual. Desde nuestra perspectiva, estos abordajes no reconocen las variabilidades históricas, sociales y culturales que moldean las prácticas de los jóvenes; las especificidades de género, de clase o étnicas según contextos regionales o locales, y, en particular, el proceso de construcción intersubjetiva y simbólica activa que los jóvenes realizan en sus particulares contextos de vida. 
Este trabajo recoge algunos resultados de la línea Género y Prevención de un programa de investigación sobre construcción social del VIH/SIDA, que desarrolla dos líneas más: Procesos de Atención y Experiencia de vivir con VIH. Desde un enfoque político y relacional esta línea indaga en las relaciones, los roles y las identidades de género en relación a la problemática de prevención del VIH/SIDA. Entendemos el género como una construcción social e histórica de carácter relacional, que se configura a partir de las significaciones y la simbolización cultural de las diferencias anatómicas entre varones y mujeres. Constituye una serie de asignaciones sociales que van más allá de lo biológico/reproductivo, desde las cuales se adjudican características, funciones, responsabilidades y derechos, es decir "modos de ser" y "actuar" diferenciales para unos y otras (Lamas, 1986). Históricamente en nuestras sociedades, supone relaciones de poder que producen y reproducen relaciones de desigualdad social entre unos y otras (Grimberg, 2001). Como un proceso en el que se conforman simultáneamente identidades, roles y relaciones sociales, se configura en una realidad "objetiva" y "subjetiva" que, al mismo tiempo que se impone a sujetos y grupos, es elaborada y reelaborada continuamente por ellos sobre la base de sus experiencias y los significados provenientes de los contextos socioculturales de los que forman parte (Ariza; Oliveira, 1996; Szasz, 2000).

En este trabajo focalizamos la iniciación sexual y algunas dimensiones de las prácticas sexuales de los jóvenes, incluyendo el cuidado sexual y su vinculación con las representaciones sobre el problema SIDA. Desde nuestra perspectiva las relaciones y las prácticas sexuales deben entenderse como modeladas por contextos socioculturales históricos, regidas por construcciones normativas y valorativas y, como resultado de y simultáneamente como productoras de relaciones de poder (Davies, 1992; Haour-Knipe; Aggleton, 1998). En este marco, nos aproximamos a la sexualidad como un complejo multidimensional de procesos de diversos órdenes y niveles, entendiendo las dimensiones biológicas y reproductivas en el marco más amplio de la cultura sexual. Este concepto permite aprehender la trama de representaciones (creencias, imágenes, valoraciones, sentimientos, temores, etc.) y prácticas específicas, cuyos sentidos pueden captarse en el contexto global de las prácticas de los conjuntos sociales (Grimberg, 1999). Consideramos la sexualidad desde tres dimensiones de análisis (Grimberg, 1995): 
a) la consideración del complejo deseo-placer y la movilidad del deseo sexual;

b) las modalidades de intercambio sexual en relación con los modelos de familia/unidad doméstica y sus cambios, la estructuración de roles en la vida cotidiana (incluida las modalidades de inserción laboral), los procesos de control y subordinación en las relaciones de género, etc.;

c) los significados sociales asignados a la sexualidad en cada contexto histórico, en relación con los modelos de género, las modalidades culturales de expresión sexual, etc. (Standing, 1992).

\section{Apuntes metodológicos}

Es imposible comprender cómo los jóvenes construyen su sexualidad y los sentidos que asignan a su iniciación o a sus prácticas sexuales, sin previamente contextualizar algunos aspectos de Argentina y de la ciudad de Buenos Aires. Como en otros países de América Latina, en Argentina se han entrecruzado y superpuesto en diferentes relaciones de poder, poblaciones y grupos de diversa procedencia étnica y cultural. A la forzada desaparición, reducción y mestizaje de poblaciones indígenas y negras y la masiva migración europea de finales del siglo XIX y primeras décadas del XX, le siguió a partir de los cuarenta, una hasta hoy ininterrumpida migración del interior y de países vecinos. Los procesos políticos, económicos y culturales resultaron en una modernidad híbrida que sin embargo, no ha podido ocultar las tensiones de las notorias desigualdades socioeconómicas y culturales entre conjuntos sociales y regiones, y en particular, las marcadas desigualdades entre la Ciudad de Buenos Aires y gran parte del país. Desde principios de los noventa las políticas neoliberales promovieron procesos de concentración política y económica que intensificaron a escala inédita la desigualdad y la vulnerabilidad social. En este contexto sin embargo, se visibilizan una serie de cambios en las relaciones sociales a nivel micro, vinculados a las modalidades, los ejes y los sentidos de las relaciones entre géneros y entre generaciones a nivel de parejas, familias y otros espacios de la vida social. Este es el escenario en el que los jóvenes construyen su sexualidad. 
Realizamos un estudio etnográfico que combina entrevistas en profundidad, observación con participación y análisis de narrativas ${ }^{3}$, a un total de sesenta (60) - mujeres y varones - de 15 a 28 años de sectores populares residentes en el cordón sur de la ciudad de Buenos Aires. Este abordaje metodológico tiene como puntos de partida: recuperar conceptualmente tanto la singularidad de los sujetos, como los contenidos colectivos; priorizar las construcciones discursivas propias de los conjuntos estudiados; focalizar la perspectiva de los actores, en particular los sentidos que los sujetos dan a las condiciones y modalidades de su vida, así como las distintas estrategias que ponen cotidianamente en juego; considerar el conjunto de escenarios y contextos para construir y analizar los datos.

El trabajo de campo fue realizado en varias etapas durante los años 1998 y 2000. Para la conformación del conjunto estudiado utilizamos una técnica de selección por criterios que requiere la definición conceptual y operacional previa de las unidades de estudio mediante la identificación de categorías. Estas fueron edad y relacionamientos de género ${ }^{4}$. Combinamos una estrategia de trabajo con informantes clave en el rol de "reclutadores" y de trabajo con redes (también denominada técnica de "bola de nieve") a partir del seguimiento de las redes de solidaridad extensa (amigos, vecinos y conocidos). La observación con participación se realizó en unidades domésticas y en actividades grupales y barriales

Los jóvenes de este estudio residen en los barrios de San Telmo, Boca, Barracas y Lugano, una de las más antiguas áreas de ocupación de la Ciudad de Buenos Aires, particularmente el primer barrio. Esta es una zona heterogénea, fragmentada en reducidos bolsones para el turismo (San Telmo y la Boca), rodeados de fabricas, depósitos y comercios en su mayor parte abandonados, edificios subutilizados correspondientes a otros momentos históricos de la ciudad, como la Aduana, el Puerto y otros organismos del Estado, edificios sindicales, casas de colectividades. No sólo los edificios y el equipamiento urbano dan señales de deterioro y precarización social, este área presenta las mayores tasas de pobreza, desempleo y subempleo e

\footnotetext{
${ }^{3}$ Este estudio continúa el Proyecto Trianual "Construcción social y VIH/SIDA. Un abordaje socioantropológico integrado en género, usuarios de drogas inyectables y personas que viven con VIH" TL068. UBACyT Programación 1998-2000.

${ }^{4}$ Edad: categoría 1, de 15 a 21 años; categoría 2, de 22 a 28 años; y categoría 3, de 29 a 35 años. Relacionamientos de género:sin pareja, con pareja conviviente y con pareja no conviviente. Entrevistamos a un total de 67 mujeres y 55 varones. Aquí presentamos datos de las dos primeras categorías.
}

Horizontes Antropológicos, Porto Alegre, ano 8, n. 17, p. 47-75, junho de 2002 
inseguridad urbana, así como un alto nivel de prostitución y tráfico de drogas ilegales. El número de hoteles de alquiler, inquilinatos y casas vacías, su ubicación en la ciudad y el acceso a servicios públicos explican en parte la concentración de migrantes en su mayor parte recientes del interior y de países limítrofes. La calle es el principal lugar de actividad laboral y social de los varones jóvenes. Estos barrios se caracterizan por la presencia permanente de grupos de jóvenes de distintas edades que mantienen la ocupación de ciertos espacios sea una esquina, la entrada de una calle, un sector de una plaza, etc.

La mayor parte de los jóvenes de este estudio viven en casas "ocupadas", inquilinatos, piezas de pensiones y "hoteles" y en menor medida en departamentos económicos de bajo alquiler. Menos de la mitad de las unidades domésticas son "nucleares" - de pareja con hijos -, la mayor parte corresponde a distintos tipos de unidades extensas. Más de un cuarto del total son unidades a cargo de una mujer, en un número importante de casos de dos o más generaciones. Por lo general proceden de la Provincia de Buenos Aires, de otras provincias y de países limítrofes.

Si bien la mayor parte de los jóvenes de este estudio eran solteros en el momento del trabajo de campo, un número considerable convivía en pareja, en particular las mujeres mayores de 21 años. Las mujeres y varones casados constituían una significativa minoría, en todos los casos el casamiento fue una decisión posterior, e incluso tras algún período variable de convivencia. Las diferencias de género son significativas tanto en el número de quienes tienen hijos, como en el número de hijos. En el primer aspecto, la relación entre mujeres y varones con hijos es de 3 a 1; en el segundo, mientras la casi totalidad de los varones se concentra entre uno o a lo sumo dos hijos, las mujeres aún en estos tramos de edad alcanzan a tres. Casi los dos tercios de las mujeres han tenido su primer hijo antes de los veinte años, siete de ellas entre los 15 y 17 años, más de la mitad "solas" (sin compañero) ya sea con o sin apoyo familiar.

La mitad tiene estudios secundarios incompletos, algunos pocos habían terminado este nivel o habían alcanzado estudios terciarios sin completar. Considerando que se trata de población urbana y joven, resulta significativo el número de varones y mujeres que no supera la escolaridad primaria (15). Sólo algo más de la mitad tenía algún tipo de ocupación remunerada, del resto la mayor parte dijo estar "desocupado" (17) o estar estudiando (12). El número de "desocupados", así como el de aquellos que manifestaron "no 
trabajar" y "no buscar", fue mayor entre los varones que entre las mujeres, entre quienes pesó la proporción de "amas de casas", en particular en mujeres con hijos pequeños. Parte de los participantes de este estudio ocupados son asalariados en distintas modalidades de condición laboral, predominantemente precarias e inestables; los otros venden por "cuenta propia" en la calle distintas mercaderías según las oportunidades diarias. En su mayor parte los empleos son "en negro" es decir sin ningún tipo de contratación legal, situación claramente más acentuada entre las mujeres ${ }^{5}$.

\section{La iniciación sexual}

Utilizamos el concepto de trayectoria sexual (Grimberg, 1999) para dar cuenta primero, de la sexualidad como proceso que no sólo se desenvuelve, sino se construye en una historia con otros, y segundo, de las singularidades de esa historia en los sujetos, sobre todo de un proceso que implica la iniciación sexual y el desempeño sexual posterior. Nuestro interés se ha centrado en las definiciones y sentidos dados por los jóvenes, y en el análisis de cuatro dimensiones: el rol de iniciativa y sus modalidades, el control de la situación, los márgenes de negociación, y el lugar del deseo y el placer.

En todos los casos, las narrativas sobre la iniciación sexual focalizaron en la penetración vaginal con el sentido de "pérdida de la virginidad". Desde este contexto interpretativo, más de la mitad de las mujeres se inició entre los 15 y los 17 años, en seis de ellas más temprano; la mayoría de los varones, entre los 15 y los 16 años. La mitad de ellas se inició con su "primer novio", las restantes con otras parejas y en menor medida con su pareja actual. Seis de los varones se iniciaron con su "primera novia", siendo esto más significativo entre los más jóvenes, la mayor parte, con mujeres mayores o bien con "prostitutas".

\footnotetext{
${ }^{5}$ Los varones en relación de dependencia trabajan en empleos municipales como obreros no calificados o técnicos, en empleos en "changas" (trabajos temporarios no calificados sin contrato legal) en la construcción, en el puerto, en distintos comercios como repositores de supermercado, en mensajeria o transporte de mercaderias. Los otros venden por "cuenta propia" en la calle mercaderias según las oportunidades diarias. Entre las mujeres, salvo una empleada administrativa municipal y otra en una escuela, las restantes en relación de dependencia y con contratos temporarios trabajan en empresas de limpieza. Quienes trabajan sin contratos lo hacen sobre todo como en tareas de limpieza en casa de familia o comercios.
}

Horizontes Antropológicos, Porto Alegre, ano 8, n. 17, p. 47-75, junho de 2002 
La mayor parte de los relatos refirieron situaciones y escenarios azarosos por las dificultades de acceder a un espacio y un tiempo propio y "apropiado" a la circunstancia desde la perspectiva de los jóvenes. Estos espacios por lo general fueron "la casa de..." algún otro - amigo, familiar, vecino -, en el caso de varones iniciados con mujeres mayores "la casa de ella", en menor medida un hotel o la propia casa y lugares abiertos de diverso tipo (patios, entradas de casas, plazas, etc.).

Tal como surge de los relatos, la iniciación sexual implicó un momento particularmente difícil en la vida de las mujeres y varones de este estudio, caracterizado por la incertidumbre y la presencia de interrogantes, temores, sobreexpectativas y presiones de todo tipo. Una significativa carencia de información sistemática y de conjunto sobre la sexualidad combinada con estereotipos sobre el amor, la sexualidad y los roles de género esperados y legitimados, configuran representaciones de "descontrol" e "imprevisión" que conforman condiciones fragilizantes para ambos. Estos componentes idealizan la situación, refuerzan el control masculino y los aspectos de subordinación de la mujer. Las construcciones de sentido y los valores asignados a la iniciación sexual por género constituyen condiciones de fragilización específicas.

En este contexto, el análisis relacionado de las dimensiones señaladas permiten reconocer algunas especificidades.

\section{Para las mujeres}

En la mayor parte de las mujeres su iniciación sexual estuvo signada por una fuerte presencia de estereotipos de carácter normativo-valorativo en torno del amor, la sexualidad y los roles de género; así como por fantasías cargadas de diversos "miedos" relacionados con el dolor, el embarazo y el abandono. Tal como señalaron Mónica y Cati:

[...] en esos momentos yo me le negaba/ eran muchas cosas que me hacían dudar/ ponele que si él no andaba con otras/ que si me quería o no/ porque no quería que después anduviera hablando o me tratara como una cualquiera/ yo soy una desconfiada/ pero no quería que después que se llega a todo él te deja (Marta, 20 años; sin pareja); 
[...] yo/ no quería primero pero él insistía/ tenía miedo/ vergüenza/ no sé/ al dolor (Cati,18 años; pareja conviviente).

En su mayor parte fue vivida como una situación contradictoria y ambivalente, no controlada por las mujeres, dominada por la iniciativa, la "presión" del varón o, en algunos casos, por formas más coercitivas: "mi primera experiencia sexual fue con mi primer pareja/ y fue este:/ una noche de terror porque yo no quería y es como que/ digamos que me forzó un poco [...] como que no/ no me gustó" (Nati, 27; sin pareja). A esta presión puede sumarse en algunos casos, la presión de pares, amigas, primas, etc., "que ya habían debutado".

[...] y bueno él insistía/ me presionaba [...] que me daba miedo/ tenía vergüenza/ todo junto/ por eso no/ no me decidía/ o sea yo ya le había dicho que sí/ pero no sé por qué no no entraba al hotel yo/ también tenía una presión de que tenía que hacer algo/ tenía dos amigas que ya habían debutado y hablábamos/ ellas me decían también que no tuviera miedo (Mariana, 25; pareja conviviente).

Si bien relatada como proceso con alternativas, la mayoría de las jóvenes identificó como iniciación un acontecimiento puntual: el momento de la "penetración", diluyendo o no reconociendo en este contexto simbólico, otros momentos y prácticas eróticas previas, así como su relación con el "desenlace". Tal como narró Liliana:

[...] no sé hacia un montón que salíamos. y unos meses que estábamos con manitos y jueguitos, pero yo no quería apurarme, ni lo pensaba [...] ocurrió de repente/ bueno estábamos solos en la casa/ pero/ bueno en realidad jugábamos/ yo no pensé/ es mas ni siquiera me di cuenta de que podíamos llegar... y así fue/ él ponía una mano y la otra y se dio (Liliana, 26; sin pareja).

Tal como se expresan en los dos testimonios anteriores y en el siguiente, la iniciación se configura en un acontecimiento fuera de su control, un "imprevisto" o algo que "ocurre de improviso" ("simplemente ocurrió”). 
[...] y un día llegamos de bailar y/ yo me acosté con él a dormir nos acostamos a dormir/ y después pasó la mano y yo pasé la mano y después ya/ [...] [risas] yo no quería pero él me hablaba/ me insistía y/ y bueno después sí [...] pero ya como estaba media picadita ${ }^{6}$ [risas] $\mathrm{y}$ al final fue como algo de improviso y rápido [...] y primero estaba temblando/ la cama se movía [risas] pero después [...] no sentí nada no/ porque tenia miedo (Maria, 17; pareja conviviente).

[...] vino sola/ claro ya al haber ido a la casa estando solos/ si/ es algo inexplicable, pero vino sola sin pensar/ yo después que: tuvimos relación yo me puse a pensar/ recién ahí yo me puse a pensar/ qué es lo que hice/ ahí recién reaccioné/ y dije qué hice/ tanto que me cuidan/ qué hice dije yo/ porque mi abuela mi tía todos me cuidaban/ (Nita, 25; pareja conviviente).

Y, sobre todo, en una situación en la que en términos discursivos, tanto el deseo como el placer no son recuperados como propios, sino subsumidos al deseo y el placer del varón.

[...] él quería/ él proponía/ yo no sabía nada y además él empezó a acariciarme/ me daba besitos/ y de pronto empezó a querer entrar y ahí me dolía/ él tenía experiencia sexual/ pero carecía de información de como lograr una buena relación y que la mujer disfrute/ él hacía pero para él/ no para mí y es el hombre el que tiene que lograr el orgasmo de la mujer (Mirta, 19; pareja conviviente).

[...] esa primera vez rarísima/ mal [...]

[¿qué sentiste?]

[...] y dolor [...] también/ me daba un poco como de bronca, que sé yo/ que por un momento fue medio brusco/ no fue tan buena como yo esperaba (Matilde, 20; pareja no conviviente).

En efecto, este tipo de discurso no incluyó términos como "ganas", "querer" u otros que hicieran referencia a la expresión de deseo propio o a una elección personal, cuando sí se los utilizó en referencia a los varones.

${ }^{6}$ Embriagada/o 
Muy pocas relataron situaciones en las que se evidenciara un papel más activo por parte de ellas en la promoción de la situación, se hiciera alguna referencia a su deseo o definiera la situación como elección personal. Para la mayor parte de ellas su iniciación sexual constituyó una experiencia no placentera, intensamente dolorosa en algunos casos, por debajo de sus expectativas en otros o simplemente un acontecimento en el que "no sintió nada".

[...] y yo no sentía/ no estaba preparada todavía/ como para hacerlo/ (y eso que en ese tema no te tenés que preparar/ eso nace)/ y yo todavía no sentía/ y yo no quería saber nada/ y el que sí/ que sí [...] y hacía un mes que convivía con él/ (pasó lo que tenía que pasar y no)/ como que no/ no me gustó (Nati, 27; sin pareja).

[...] o sea fue lindo todo menos el momento de la penetración que fue horrible porque me re-dolió y/ bueno/ por un montón de tiempo no pude/ no sé si era porque estaba nerviosa o porque no pude. Y hasta llegué a pensar que yo tenía algún problema porque no podía [...] pero a lo último/ no sé si él se habrá dado cuenta porque nunca lo hablamos. Y como él nunca me decía nada/ a veces yo terminaba llorando y él ni se daba cuenta (Lia, 21; sin pareja).

[...] yo pensaba que iba a ser más emocionante no/ no sé/ lo tomé después como una cosa/ no sé/ después que pasó no me gustó después/ el dolorcito y las molestias bueno pero no fue lo que/ lo que esperaba qué sé yo sentir algo/ eh: más placentero (Juana, 16; pareja no conviviente).

Las escasas informantes que relataron la experiencia en términos positivos hicieron una recuperación más afectiva que erótica.

[...] fue una experiencia linda porque fue la primera vez de tener un hombre y decir/ bueno un hombre/ pero en la cama digamos que no sentí lo mismo/ a mí me gustaba como era él/ la cara el físico eh todo pero/ aparte era muy tímida/ y no me gustó desnudarme adelante de él y todas esas cosas [...] y bueno sentí vergüenza/ pero tambien sentí: alegría (Cristina, 22; pareja no conviviente). 
[...] fue muy linda/ muy preparada por los dos/ muy conversado todo porque yo tenía mucho miedo/ pero fue muy linda porque fue con mucho cuidado despacio y entre los dos viendo/ si yo quería así o si me dolía esas cosas cuando una pareja se entiende (Teresa, 17; pareja no conviviente).

\section{Los varones}

La iniciación masculina aparece fuertemente definida como afirmación de la identidad, y en tal carácter como rito de pasaje. En esta articulación de sentidos se instituye en un acontecimiento tenso/ contradictorio al que se arriba con temor y desconocimiento: "yo tenía 14 y ella tenía 18 o 19 y todos los días curtimos ${ }^{7}$ pero yo no estaba seguro porque a esa edad no sé/ yo no sabía/ tenía miedo a fallar/ me entendés/ tenía un miedo bárbaro" (Tomi, 20; pareja no conviviente).

Los relatos componen una situación en la que juegan tanto la solidaridad como la presión de las redes del barrio, compañeros de estudio y familiares (hermanos, primos, cuñados), configurándose para algunos en "situación" a la que "se llega arrastrado".

[...] yo te digo asumo que fui totalmente cagado ${ }^{8}$ y que/ bueno/ si era por mi por mi voluntad/ yo no iba/ yo no iba loco/ llega una situación en que vos no podés escapar/ sabés cuál era mi miedo/ no conocer los elementos con que estaba trabajando pero fui arrastrado por los chicos $[\ldots]$ tenía miedo al papelón/ miedos pero después se te pasa (Ricardo, 28; pareja conviviente).

Para otros, en casi exclusivo centro de preocupación e interés, o como expresó uno de los varones en una "obsesión": "te digo/ a mi lo único que me interesaba era el sexo/ las revistas/ todo lo porno/ estaba obsesionado/ tenía que $\operatorname{coger}^{9}$ con alguien/ no te niego que tenia un poco de miedo/ pero era una obsesión" (Diego, 27; pareja conviviente).

\footnotetext{
${ }^{7}$ Encuentros o contactos sexuales que pueden implicar o nó prácticas de penetración.

${ }^{8}$ Con miedo.

${ }^{9}$ Contacto sexual con penetración.
} 
Es experimentada como un "aprendizaje", tanto cuando se realiza en manos de "expertas" - trabajadoras sexuales o mujeres de más edad -, o cuando supone una iniciación compartida:

[...] fui con unos pibes a un lugar [...] y yo fui y la vi/ la mina ${ }^{10}$ se abrió de gambas ${ }^{11}$ y me dijo esto es así así y así qué sé yo [...] pagué/ me dice bajate los pantalones/ vení/ yo era chico qué sé yo/ y pasó [...] usé forro ${ }^{12}[\ldots]$ eh: me dijo cómo se tenía que poner (Hugo, 21; pareja no conviviente); empezamos con cositas y jueguitos/ ninguno de los dos sabía nada/ teníamos la misma edad [cuantos años] 15/ en realidad nos inspirábamos en las películas de la tele/ yo me sentía más responsable por saber/ pero fui aprendiendo (Luis, 24; pareja no conviviente).

Resulta um "momento necesario" en la que "dejar de ser virgen" equivale a confirmar la propia identidad masculina; en una prueba privada - frente a sí - y pública - frente a los pares: "sentí que no sé/ me sentí un hombre/ te digo la verdad/ me sentí un hombre" (Gerardo, 18; pareja no conviviente); "para mí/ bueno $[. .$.$] / ser hombre/ ahí con los otros chicos" (Tito, 16; sin pareja).$

Pero sobre todo, es significada como una prueba en la que identidad masculina equivale a "heterosexualidad" "y ya era hombre viste claro [risa] me gustó... porque sino seria del otro bando" (Juan, 23; pareja conviviente); "si no no/ me hubiera hecho del otro gremio" (Roberto, 21; sin pareja).

Independientemente de a quién se atribuya la iniciativa de la situación, los varones se presentaron a sí mismos como protagonistas, ejecutores o realizadores de la acción. Aún reconociendo "desconocimientos" y "temores", los relatos mostraron una clara recuperación no solo del deseo, sino de sus iniciativas y direccionamientos sexuales, así como del placer logrado. Tal como narró José su experiencia con una mujer de más edad:

[...] ella me pidió salir/ le dije que sí después salimos un par de semanas y/ yo le dije que si quería coger y/ nada más/ y después me la cogí nomás [...] llegamos eh/ [...] tomamos algo y después ella me

\footnotetext{
${ }^{10}$ Mujer con distintas acepciones valorativas según el contexto discursivo.

${ }^{11}$ Piernas.

${ }^{12}$ Camisinha.
} 
dijo/ bueno me llevó a la habitación de ella y me empezó a $\operatorname{arrimar}^{13}$ y luego nos desnudamos y me la cogí (José, 17; sin pareja).

En los casos de iniciación sexual conjunta, resulta claro el papel dominante del varón en términos de iniciativa y control del conjunto de la situación, así como desde los roles de género, el lugar asignado a la mujer: acompañar, resistir y finalmente ceder.

[...] en la casa estábamos mirando/ no/ estábamos escuchando música en la pieza y ella estaba haciendo los deberes/ las tareas del colegio y yo me calenté y empecé a meter la mano de frente march/ nos tiramos en la cama y ella no quería/ no quería hasta que aflojó y lo empezamos a hacer

[¿habían hablado de acostarse en algun momento o de algo así?] no para nada (Gerardo, 18; pareja no conviviente).

En este contexto, las expectativas del rol de género y los estereotipos asociados a la "masculinidad", así como el marco global de las condiciones de realización (desconocimientos, temores, carencia de redes de contención adecuada, etc.) constituyen las principales fuentes de vulnerabilidad para los varones.

Un último aspecto a señalar, las narrativas de los varones muestran con mayor claridad a la iniciación sexual como rito de pasaje, especialmente aquéllas que se realizan con mujeres mayores o con trabajadoras sexuales; sin embargo, parte de sus características, en particular el marco de un espacio social compartido con los pares, está presente en su significación en las iniciaciones sexuales compartidas. En este sentido se configura en puente simbólico hacia una identidad de varón adulto legitimada por "otros" semejantes. Tal como aparece en los relatos, la iniciación sexual inaugura al mismo tiempo la vida adulta y una identidad "legítima": la de "hombre" en términos de varón heterosexual. Como ritual posibilita una forma socialmente sancionada, que constituye lo obligatorio en deseable (Turner, 1988), afirma un sentido de pertenencia e inclusión en la categoría social de hombre. En otros términos proporciona maneras socialmente legitimadas para construir la experiencia y dar sentido a las acciones, sentimientos y pensamientos individuales (Douglas, 1973).

${ }^{13}$ Acercamiento sexual, se usa para los primeros momentos de contacto. 


\section{Relacionamientos sexuales y estereotipos de género}

La mayor parte de las mujeres y varones refirieron distintas modalidades de relaciones con términos como: "pareja", "salir con", "relaciones", "transas" etc. La mayoría de las jóvenes relataron mas de dos relaciones a las que definieron como "estables", incluyendo experiencias sexuales en el marco o no de convivencias. Fuera de éstas reconocieron un número variable de relacionamientos sexuales "no estables". El "amor" o el "estar enamorada" constituyó entre las mujeres el principal parámetro de diferenciación para discriminar entre "novios/parejas" y "relaciones" o "transas". Sin embargo, mientras las mayores de 25 años, sobre todo quienes estaban en pareja, hicieron más énfasis en sus relaciones de "pareja estable" y en "el amor", las menores de 25 años refirieron un mayor número de relacionamientos y encuentros sexuales en los que primaba sólo "las ganas", "el estar bien", entre otras expresiones:

[...] para la mujer no es solo sacarse la calentura [...] otra cosa es que salgas con el pibe y llegues/ llegues a hacerlo/ pero no siempre estas perdidamente enamorada porque/ eh a veces curtis/ curtir es verse mas seguido, te gusta alguien y lo ves o te vas con él seguido/ bueno te cuento/ con dos/ el año pasado y éste (Ana, 17; años sin pareja).

Además del "amor", el "conocimiento" y la "confianza" funcionan como reaseguros para relacionamientos sexuales, tal como lo expresó una de las jóvenes: "además de dos parejas/ yo salí con otros porque me gustaban/ tenía ganas/ pero amor no era/ les tenía confianza, eran compañeros no me iban perjudicar" (Lila, 21; años sin pareja).

Los varones relataron un mayor número de relacionamientos, "novias" o parejas a lo largo de su vida. En las trayectorias de los varones la distinción de modalidades de relacionamientos adquiere una significación particular, destacándose:

Las relaciones con "novias oficiales" o "formales", en cuya caracterización jugaron como criterios los de "seriedad", "respeto", "confianza", en términos de opuestos a "atorrantear": "tres novias/ la primera/ [...] me sirvió para/ notar una diferencia de lo que era salir con una chica a no salir/ la segunda/ [...] fue medio como que más serio/ pero bueno luego me puse a atorrantear ${ }^{14 ”}$ (Anibal, 17; sin pareja)

\footnotetext{
${ }^{14}$ Tener relaciones sexuales con distintas parejas al mismo tiempo, es un verbo extensión de "atorrante": calificativo moral para personas que engañan, estafan, "viven de los otros", etc.
}

Horizontes Antropológicos, Porto Alegre, ano 8, n. 17, p. 47-75, junho de 2002 
Los relacionamientos eventuales con las "otras", las "chicas de fin de semana", "de una noche", las "transas"15 tal como surge en el siguiente relato:

[...] estuve con P. y me enganché? que fue a los dieciocho casi diecinueve/ por ahí/ y empecé a salir con ella y bueno y ya me quedé con ella/ pero si no siempre de acá para allá con chicas de fin de semana/ transas/ nunca nada fijo [...] mis amigos me decían bueno esta viene fácil entonces yo iba/ encaraba/ transabamos toda la noche y despues nada (Juan, 23; pareja conviviente).

Un aspecto particularmente relevante surgió en los tramos de entrevistas en los que indagamos con qué tipo de relaciones habían o no tenido relaciones sexuales. Como señaláramos, mientras las explicaciones y referencias de las mujeres estuvieron centradas en "el amor" o "el enamorarse", o en "la seguridad", "la confianza", "el conocimiento"; las argumentaciones de los varones - "con todas las que pude", "con las que me dejaron" - ponen de manifiesto dos cuestiones que creemos son significativas:

Una primera, más inmediata, la mayor parte de las narrativas de los varones colocan a la mujer en el lugar de poner límites, de posibilitar o "frenar". Sin embargo, y quizás esto es lo más significativo: a nivel de la percepción sólo dos de las mujeres incluyeron en sus respuestas alguna autoreferencia en estos términos.

Una segunda, una visión compartida por varones y mujeres de la sexualidad masculina como "predisposición", "necesidad" o "condición natural" siempre activa: "el hombre para coger esta dispuesto todo el tiempo [...] Es una necesidad para el hombre/este:/ por eso digo que estás siempre dispuesto creo que es eso" (Mario, 25; sin pareja); "para los varones el sexo es parte de su naturaleza, ellos tienen una necesidad mas física/ es permanente" (Alicia, 24; pareja no conviviente).

15 Ver nota 7. 
Sexualidad que es al mismo tiempo condición de afirmación de la propia identidad y de los espacios de sociabilidad, tal como lo expresaron algunos de los jóvenes: "y coger es en un grado/ eh para mostrar eh el machismo/ me entendés [...] fijate si te cogés a una sola/ entrás en la rama de los medio boludo [...] porque/ este/ no te cogés a nadie/ ahora si venís volteándote a medio mundo sos un piola bárbaro" (Riki, 22; pareja no conviviente); "y si para mí una hombría es como decir soy lo máximo/ te quiero coger" (Mario, 25; sin pareja).

Desde ésta construcción, para los varones las mujeres "deben ser ganadas" a través del "convencimiento" y la "insistencia" ("no acepto un no"). "yo doy tiempo/ no me gusta apretar enseguida/ aunque sepa que la mina puede ser fácil/ me gusta ganármela/ pero no me gusta que se me haga la difícil/ si veo que la situación ya viene/ que empezamos a curtir y ella responde/ eh entonces no acepto un no" (Fede, 26; sin pareja); "porque una mujer/ no se te va a entregar fácilmente y si la mujer se te entrega fácilmente/ me entendés y te hace cosas que/ que te pueda dejar alucinado/ yo puedo llegar a pensar loco que la chabona puede llegar a tener algo" (Hugo, 19; sin pareja).

Esta construcción delimita un modo de accionar en términos de iniciativa (del varón) y "resistencia" (de la mujer), a la vez que muestra la fuerza de una tipología clasificatoria moral de la mujer que distingue entre las que "resisten" o "se dejan": "algunas que son fáciles... transan y ya está... y hay otras que no les cabe la transa, qué sé yo" (Mario, 25; sin pareja); "sí porque me transé a tal/ me transé a cual viste/ esas minitas... loquitas también las putitas/ no sé a veces las ves viste [...] cerca de la Boca viste y pensás esta puta a cuántos se habrá apretado, yo conocí a una mina que transaba con dos o tres viste" (Luis, 22; pareja no conviviente); "hay mujeres que supongo que les gusta/ yo lo hablo me ha pasado/ eh que a veces querés saber que piensan antes de llegar a algo/ y te dicen no que esto es una transa y nada más bueno esta bien/ entonces termina en que ellas te transaron" (Héctor, 28; pareja conviviente).

Parte sustancial de estas construcciones es una visión dicotómica que, tanto entre mujeres como varones, distingue "acto sexual" o "hecho físico" de "amor" o "hacer el amor". En todos los casos, una manifiesta tensión entre el orden de "lo físico" y el del "amor" define y separa "tipos" de relacionamientos. Tal como señaló una de las jóvenes: "una relación sexual se puede tener con cualquiera/ que/ o con alguien que te guste aunque no 
lo quieras, aunque que sé yo, porque tenés ganas y listo. En cambio, cuando hacés el amor es otra cosa, estás enamorada" (Lila, 21; años sin pareja). Entre los varones esta distinción evidencia marcas claramente morales:

[...] en unas transás y en otras hacés el amor... no es el mismo beso que vos le das a tu novia que le das a otra persona, vos te cuidas con tu novia de una forma y con la otra no/ digamos hasta en la profilaxis digamos no?/ yo hago una divisoria de aguas/ la satisfacción fisiológica el estar bien el gozar son dos cosas diferentes/ uno es un goce de amor y el otro puede ser hasta un goce fisiológico/ no sé (Ernesto, 27; pareja no conviviente).

[...] el amor... uno lo tiene que hacer con su pareja porque la amás/ ahora tener relaciones es como decir qué sé yo me echo un polvo y nada más porque lo hacés/ por naturaleza no por amor y lo haces con cualquiera (Marcos, 25; pareja conviviente).

Como hemos señalado en otros trabajos, el análisis de las prácticas sexuales pone al descubierto el peso de una construcción biológico-moral dominante de la sexualidad - como heterosexualidad exclusivamente reproductiva - que delimita la frontera entre sexualidad "normal" y "anormal" (Grimberg, 1999, 2001) e instituye prácticas como "naturales" y "no naturales". Esta construcción:

sostiene una representación dicotómica de las relaciones sexuales que separa y pone en tensión "hecho/ acto físico" y "afecto/ amor";

escinde y coloca el deseo, el placer y la iniciativa sexual en el varón, y la aceptación-concesión en la mujer, constituyéndose "el amor" entre éstas en requisito, garantía y justificación de la práctica sexual. Su articulación a una noción romántico-altruista del amor, coloca a la mujer en el lugar de la entrega, el sacrificio y la concesión.

Desde estos estereotipos de género, el rol de la mujer no es sin embargo pasivo. Los relatos ponen en evidencia una diversidad de prácticas tanto asignadas como efectivas de distinta significación. Por un lado, tal como señalan explícitamente los varones, es parte del rol de la mujer el responder de alguna manera, el "decir sí o no" o el "poner límites". 
[...] yo avanzo/ empiezo a apretar y empiezo a franelear/ si la mina me para/ no? paro y digo qué te pasa/ no sigo si la mina me esta frenando/ si no dice nada bueh vuelvo a seguir no?/ y mientras más se vaya dejando más más avanzo [...] para algunas cosas a veces tiene que estar muy caliente si no/ a veces se lo pedís y ella no quiere viste (Luis, 22; pareja no conviviente).

Por el otro, se reconoce de manera manifiesta y se hace énfasis en un rol de género explícitamente inductivo de "seducir", tal como relataron dos de los varones conviviendo en pareja:

[...] y ella también/ ella si... bueno a ella si, a ella le gusta insinuarse mucho/ no/ por ejemplo el otro día me dijo/ estábamos los tres con C./ y dice/ y agarra y dice: bueno C./ ¿cuándo te dormís que con papá tenemos que hablar?/ a ella le gusta ese tipo de insinuaciones/ o capaz se está probando una ropa que se compró o un:: qué sé yo/ un corpiño que se compró y me dice: te gusta y me mira así medio reventada/ esa es la forma de insinuar de ella (Juan, 23; pareja conviviente);

[...] vengo re filtrado del laburo y estoy muerto lo único que quiero es tomarme un par de cervezas/ mirar la tele y después dormirme [...] y ella jode se te sienta arriba viste [...] se te mete con el camisón viste transparentito/ seduce y por ahí muchas veces apago la tele y aprovecho pero viste generalmente todos los días [...] lo único que querés es decirle alcanzame las ojotas que me siento adelante de la tele dame una lata de birra (Lito, 27; pareja conviviente).

Los espacios de juego entre ambos aspectos del rol sostienen las categorías clasificatorias, marcando las distinciones entre "buenas" y "malas" mujeres.

En efecto, el peso de un "deber ser como mujer", por ejemplo el expresar desconocimiento e inexperiencia sexual, "el tener que esperar", "hacerse la difícil", "poner resistencia", etc., instituidos como "comportamientos esperados" y necesarios para el desempeño de los roles masculinos, limitan la iniciativa y capacidad de negociación de las mujeres, ya sea como componentes del imaginario o como experiencias concretamente vividas: 
[...] antes lo buscaba/ pero después de algunas situaciones/ bueno el empezaba con preguntas o con celos/ como a pensar mal de mi/ bueno listo ahora siempre es él el que empieza/ yo me hago la desentendida/ y lo dejo hacer/ tambien cuando uno está de novio es una cosa/ cuando vive es otra (Ines, 22; pareja conviviente).

[...] a mí me gustaba muchísimo/ me parecía un tipo genial pero no quería que el se diera cuenta/ así que salíamos y él intentaba apretarme y yo nada/ y así me mantuve un montón/ incluso después que empezamos a acostarnos/ yo siempre me hago la difícil/ la que responde pero nada más/ para mi es la única manera de mantenerlo interesado (Cristina, 22; pareja no conviviente).

En síntesis, las características de las relaciones de género, en términos de los roles atribuidos a cada uno en los relacionamientos y de los sentidos dados a la sexualidad y las prácticas sexuales, así como el vigor de estereotipos clasificatorios de la mujer de fuerte contenido moral, constituyen la estructura de desigualdad que mantiene la iniciativa y control en manos del varón, refuerza en algunos casos los aspectos de subordinación de la mujer, mientras que en otros reduce los márgenes de negociación o limita las posibilidades de asumir formas más activas por parte de las mujeres de sectores populares.

\section{Protección sexual y VIH/SIDA}

Los jóvenes participantes de este estudio manifiestan diversos grados de conocimiento en torno del cuidado sexual, y de manera más particular, de las distintas formas de protección sexual y sus funciones. El preservativo resulta la forma de protección que más indican cuando se indaga el conocimiento de las formas de prevención del embarazo, de enfermedades de trasmisión sexual (enfermedades - infecciones) y del VIH/SIDA. Sin embargo, el uso de preservativos es significativamente bajo en el ámbito de las prácticas efectivamente realizadas, tanto durante la iniciación como en los relacionamientos sexuales posteriores. Los jóvenes - varones y mujeres - de la primera categoría de edad (15 a 21) son quienes indicaron una mayor frecuencia de uso. 
El uso de preservativo resulta una práctica eventual en dos sentidos:

Como práctica acotada a los momentos iniciales de una relación de pareja. Un importante número de jóvenes, varones y mujeres reconoce "haber usado y dejado" cuando su pareja adquirió "estabilidad".

[...] sí usábamos primero eh: usábamos profilácticos ${ }^{16}$ después cuando la relación se hizo más estable empecé a tomar pastillas este: y bueno pastillas y alternábamos entre pastillas y profilácticos/ en principio era el tema de: bueno siempre es el embarazo ¿no? eh el de no quedar embarazada y bueno este: al principio por eso usábamos profilácticos porque qué sé yo/ como uno no se conoce tanto no sabe qué paso qué sé yo/ cuando se tiene confianza/ en todo sentido/ digamos de que la relación es estable ¿no? de que: qué sé yo no sé de golpe iba a la casa ya no era lo mismo/ se van dando un montón de cosas uno va conociendo el entorno de él no es que sea alguien re descolgado/ no sé cuándo se produce es específicamente ese cambio pero: bueno fue así (Pepa, 25; pareja no conviviente, 2 hijos).

También acotado a relacionamientos ocasionales:

lo uso en una relación de un momento o de una noche/ no lo uso con mi mujer/ lo usaba/ eso desde ya/ y con mis novias también lo usaba un cierto período y después no lo usaba cuando más o menos conocía bien a la pareja/ cuando conocía bien cómo era la otra persona y la otra persona me conocía a mí (Marcos, 25; pareja conviviente).

Como uso alternado con otros métodos de cuidado o simplemente con ninguno en el marco de relaciones definidas como "estables". La mayor parte de las mujeres indicaron usar preservativo sólo como método alternativo durante el descanso de píldoras anticonceptivas.

El uso de preservativo es mayor entre los varones, si bien con diferencias según el tipo de relacionamiento. Este es menor entre aquellos que se encuentran en situaciones de pareja (conviviente o no). A su vez, la mayor parte de quienes reconocieron relaciones ocasionales o paralelas, sólo usaba preservativos con éstas últimas y dos de ellos sólo "a veces". 
Entre los varones sin pareja el preservativo resultó la forma más común de protección sexual aunque su uso es sólo eventual en la mayor parte de los mayores de 20 años.

Esta práctica está condicionada por diferentes tipos de mediadores, entre ellos:

La identificación de más desventajas que ventajas en su uso. La dimensión del placer aparece sobre todo por la negativa, del lado de las desventajas: "te baja la sensibilidad", "disminuye el placer": "en lo mejor le decís pará es lo mismo que estar al repalo/ hasta que vas/ sacás el forro/ lo abrís y te lo ponés/ baja la intensidad/ viene a ser como medio mecanizado/ enfría a la minita/ te dice ponémela/ vos decís esperáme un cachito" (Luis, 22; pareja no conviviente).

Esta identificación negativa en relación al placer masculino, se encuentra en la base de la aceptación naturalizada de la resistencia del varón o de su explícita negativa en la mayor parte de los relatos de las jóvenes ("él no siente"): "a los hombres no les gusta/ no quieren usarlo por un lado está bien que lo usen y por otro lado no porque ellos/ no sienten nada/ yo quiero pero algunas veces él no quiere porque se incomoda/ dice uf siempre con esta goma entonces [risas]" (María, 17; pareja conviviente, 1 hijo).

Una representación de la sexualidad masculina asociada con la "naturaleza" como "fuerza incontenible", que configura las relaciones sexuales en términos de una "intensidad tal" o "un impulso del momento" que "no da tiempo" para el cuidado. A contracara, el peso de imágenes del preservativo como una interrupción, como "algo externo" que "corta" el flujo de la relación: "que te digo, no sél es como no sé hablando mal y pronto por la calentura/ nos desesperamos bueno es un decir y ahí que sé yo no nos damos cuenta de cuidarnos" (Inés, 22; pareja conviviente, 3 hijos); "no siempre lo uso/ no/ si yo estoy tan caliente que no me doy cuenta de ponérmelo/ no sé/ no puedo interrumpir" (Juan, 23; pareja conviviente).

Una representación predominante del preservativo como masculino, un "asunto de hombres", iniciativa y responsabilidad del varón (uso efectivo, compra, tenencia, momento y características de su colocación) a partir de la cual la capacidad de intervención de la mujer se reduce a solicitar. "hay veces que no tengo/ me molesta que siempre tenga que 
ser yo el que compre/ que lleve/ ellas esperan o piden pero ¿por qué no se responsabilizan también?" (Ale, 24; pareja no conviviente); "siempre no se cuida/ se olvida de comprar o creía que tenía cantidad y ya lo había terminado" (Alicia, 24; pareja no conviviente).

La asociación por la negativa o en términos de oposición al "conocimiento y la "confianza" (uso para los momentos iniciales de una relación o para encuentros ocasionales) pone de manifiesto que en esta línea de significación "conocimiento" y "confianza" no solo refieren a un saber "de enfermedades", sino sobre todo, a un saber de la "conducta" del otro.

[...] y bueno porque eso va en el sentimiento de cada uno/ no/ te das cuenta de la persona cómo es y: que no es lo mismo usarlo con el profiláctico y bueno las veces que yo lo usé porque tenía miedo de todas las enfermedades/ del SIDA/ y porque el temor a las enfermedades desaparece cuando ya conocés a la persona/ porque vos al principio pedís preservativo y después no/ que cuando vos conocés a la persona ya no (Cora, 22; sin pareja, embarazada).

Un saber moral cuyos soportes básicos son las nociones de estabilidad y fidelidad. Así, mientras el no uso de preservativo afirma un "saber" de "que no anda con otra-otro"/ "no ando con otro-otra"; el uso o el mero hecho de solicitar, no sólo puede implicar actualizar o hacer presente la posibilidad, sino también de alguna manera admitir y contradictoriamente legitimar la "infidelidad".

La resistencia del varón y/o su directa negativa al uso, así como la emergencia de situaciones conflictivas, que ponen de manifiesto las relaciones de poder, los variables y escasos márgenes de presión y las dificultades de negociación por parte de las mujeres (aún cuando insistan y/ o recuperen la dimensión del placer). "y a veces le digo que así no/ ponéte el forro/ y le insisto pero termino por darle el gusto [...] y qué sé yo/ es el momento y a veces lo mando a la miércoles y listo" (Alicia, 24; pareja no conviviente, 1 hijo); "lo que pasa es que hay que darle el gusto si no se pone pesado/ y hay que aguantarlo/ qué sé yo nervioso/ al final me resigno" (Susana, 28; pareja conviviente, 6 hijos). 
Asociados a esta línea de significación interesa destacar dos núcleos de sentido más:

El primero, en varios casos el uso del preservativo es vivido como una concesión del varón, como algo que el varón concede y hace a disgusto, parte de un proceso de intercambio y concesiones tambien para la mujer: "me pide algunas cosas y bueno como para/ que encima que se cuida/ bueno entonces como para que esté bien yo hago" (Marita, 25; pareja no conviviente). El segundo deriva de atributos del embarazo como medio de manipulación femenina en función de producir o mantener la alianza, en términos de las jóvenes de este estudio: como "enganche": "el hombre se cuida cuando no quiere que lo enganchen ${ }^{17 "}$ (Luisa, 27; sin pareja). Desde ahí, los relatos muestran sistemáticas tensiones en las que usar o no usar preservativos, puede ser indistintamente valorados en términos positivos o negativos desde la esfera afectiva.

- "Se cuida conmigo porque no quiere que lo enganche"

- "No se cuida conmigo porque no le importa que lo enganche"

Estas modalidades y sentidos están presentes en la aproximación al problema VIH/SIDA. Si bien, en términos generales tanto varones como mujeres ponen de manifiesto información sobre las formas de trasmisión, como hemos señalado en otro trabajo (Grimberg, 2001) el peso de categorías normativomorales fuertemente estigmatizantes de sujetos y comportamientos, introduce confusiones y notables ambivalencias en el contexto de las representaciones y las prácticas. El "SIDA" emerge espontáneamente como problema durante distintos tramos de las entrevistas, poniendo de manifiesto una percepción simultánea como "enfermedad" y como problema de "seguridad". Significativamente sin embargo, aparece muy débilmente en aquellos tramos auto referenciales, por ejemplo relatos de distintos tipos de relaciones sexuales, problemas que le preocupaban personalmente, temas hablados con familiares o amigos, etc. En este marco si bien su delimitación como problema social resulta clara, se ubica más como un problema de "otros", externo al espacio particular de sus preocupaciones personales.

Si bien nuestro estudio muestra distintas valoraciones del problema, lo dominante es una construcción normativo-moral que asocia VIH/SIDA a 
"droga"/ "promiscuidad"/ "homosexualidad". Esta construcción centraliza en el "contagio", configura a quienes lo padecen en un "otro" peligroso, refuerza visiones generalizantes y estigmatizantes de "descontrol", "promiscuidad", "droga", "relaciones sexuales ocasionales", "relaciones sexuales con desconocidos" como condiciones causales; a la vez que sostiene un imaginario de garantías y seguridades morales en los preceptos de "cuidarse", "no drogarse", tener "pareja estable", usar "preservativos con desconocidos" o en las "relaciones ocasionales".

\section{Notas para la reflexión}

Los procesos de prevención, y en particular aquellos que incluyen cuidado sexual, constituyen problemáticas complejas y multidimensionales con sentidos no sólo ambivalentes sino notablemente contradictorios. Sus significaciones así como las formas concretas que asume pueden entenderse desde las relaciones, roles e identidades de género, a los que debe articularse el peso y las particularidades de la construcción social del problema VIH/ SIDA.

Como hemos señalado las posibilidades concretas de su prevención no pueden considerarse de manera aislada; gravitan modos de vida, así como modalidades específicas de relación social y sexual en las que son relevantes el entramado de relaciones de poder que sostienen estereotipos y roles de género.

En el marco de las relaciones de poder que organizan las relaciones de género y su expresión en la sexualidad, la fuerza de un "deber ser" como mujer y como varón, instituidos en "comportamientos esperados" y "necesarios" para el desempeño de los roles, fortalece la iniciativa y el control de las relaciones sexuales en manos del varón, limita la iniciativa y capacidad de negociación general de las mujeres, a la vez y tal como lo muestran los datos presentados, somete a éstas a prácticas que tensan los oscuros límites entre "presionar" y "forzar", entre coerción y violencia sexual.

Estos estereotipos dificultan en las mujeres reconocer el propio deseo, a la vez que legitiman prácticas coercitivas por parte del varón como aspecto "natural" del rol de la mujer. La articulación a otras desigualdades sociales en relación con el acceso y el control de recursos materiales y simbólicos, o la autonomía y la capacidad de tomar decisiones en los restantes ámbitos de la 
vida cotidiana, constituyen condiciones de vulnerabilidad diferenciales en mujeres y varones jóvenes de sectores populares.

Mirada de conjunto, la problemática del VIH/SIDA en relación con los jóvenes descubre la gravitación de procesos socioculturales y políticos que naturalizan las relaciones sociales y sexuales de género, oscurecen los aspectos de subordinación, y sobre todo, tienden un velo que no permite ver (y apropiar) las resistencias y las pequeñas iniciativas o transformaciones que las mujeres y los varones realizan cotidianamente.

\section{Referencias}

AMUCHASTEGUI, A. Dialogue and negotiation of meaning: constructions of virginity in Mexico. Culture, Health and Sexuality: an International Journal for Research, Intervention and Care. London, v. 1, n. 1, p. 79-93, 1999.

ARIZA; OLIVEIRA, O. Acerca de la condición femenina: propuesta de un marco analítico. México: El Colegio de México, 1996.

CAMPBELL, C. Women, families \& HIV-AIDS: a sociological perspective on the epidemic in America. Cambridge: Cambridge University Press, 1999.

CARDOZO, R.; SAMPAIO, H (Org.). Bibliografía sobre a juventude. São Paulo: Edusp, 1995.

DAVIES, P. On relapse: recidivism or rational response? In: AGLETON, P.; DAVIES, P.; HART, G. (Ed.). AIDS: rights, risk and reason. London: Falmer Press, 1992.

DOUGLAS, M. Pureza y peligro: un análisis de los conceptos de contaminación y tabú. Madrid: Siglo XXI, 1973.

FIGUEROA-PEREA, J. G. Algunos elementos para interpretar la presencia de los varones en los procesos de salud reproductiva. Cadernos de Saúde Pública, Rio de Janeiro, v. 14, n. 1, 1998.

FULLER, N. Identidades masculinas: varones de clase media en el Perú. Lima: Pontificia Universidad Católica del Perú, 1997.

FULLER, N. Cambios y continuidades en la identidad masculina. Ponencia al VI Congreso Latinoamericano de Ciencias Sociales y Salud. Lima, 2001. Mimeografado. 
GILMORE, D. Manhod in the making: cultural concepts of masculinity. New Haven: Yale University Press, 1990.

GRIMBERG, M. Sexualidad y construcción social del SIDA: las representaciones médicas. Cuadernos Médico Sociales, Rosario, n. 68, 1995. GRIMBERG, M. Sexualidad y relaciones de género: una aproximación a la problemática de la prevención al VIH/SIDA en sectores populares de la ciudad de Buenos Aires. Cuadernos Médicos Sociales, n. 75, p. 65-76, 1999.

GRIMBERG, M. "Saber de SIDA" y ciudado sexual en mujeres jóvenes de sectores populares del cordón sur de la ciudad de Buenos Aires: apuntes para la definición de políticas de prevención. Cadernos de Saúde Pública, Rio de Janeiro, v. 17, n. 3, p. 481-489, 2001.

HAOUR-KNIPE, M; AGGLETON, P. Social enquiry and HIV-AIDS. Critical Public Health, London, v. 8, n. 4, p. 257-271, 1998.

KAUFMANN, M. Las experiencias contradictorias del poder entre los hombres. In: VALDÉS, T.; OLAVARRÍA, J. (Org.). Masculinidades: poder y crisis. Santiago: Ediciones de las Mujeres, 1997.

KEIJZER, B. de. La masculinidad como factor de riesgo. Ponencia a la V Reunión Nacionnal sobre la Investigación Demográfica en México. México, 1995.

KEIJZER, B. Hasta donde el cuerpo aguante: género, cuerpo y salud masculina. Ponencia al VI Congreso Latinoamericano de Ciencias Sociales y Salud. Lima, 2001.

KIMMEL, M. A produção simultânea de masculinidades hegemônicas e subalternas. Horizontes Antropológicos, Porto Alegre, v. 4, n. 9, 1998.

LAMAS, M. La antropología feminista y la categoría género. Nueva Antropología, México, v. 8, n. 30, 1986.

MADDALENO; MUNIST; SERRANO et al. La salud del adolescente y del joven. Washington: Publicación Científica, 1995. (Organización Panamericana de la Salud, n. 552).

MESSNER, M. Politics of masculinities: men in movements. London: Sage, 1997. 
MINISTERIO DE SALUD. Unidad Coordinadora Ejecutora VIH/SIDA y ETS. Boletín de SIDA: Programa Nacional de Lucha contra los Retrovirus del Humano y SIDA, mayo 2001.

OLIVEIRA, M. (Org.). Cultura, adolescência e saúde: consórcio de programas em saúde reprodutiva e sexualidade na América Latina. Campinas: Unicamp, 2000.

ROTH, N.; HOGAN, K. (Ed.). Gendered epidemic: representations of women in the age or AIDS. London: Routledge, 1998.

STANDING, H. AIDS: conceptual and metholological issues in researching sexual behavior in Sub-Saharian Africa. Social Science and Medicine, v. 34, n. 5, 1992.

SZASZ, I. Género y salud: propuestas para el análisis de una relación compleja. In: BRONFAN, M.; CASTRO, R. (Org.). Salud, cambio social y política: perspectivas desde América Latina. México: Instituto Nacional de Salud Pública y Foro Internacional de Ciencias Sociales y Salud/Edamex, 1999. p. 109-121.

TURNER,V. El proceso ritual: estructura y anti-estructura. Madrid: Taurus, 1988.

WATSON, J. Male bodies: health, culture and identity. Londres: Open University Press, 2000. 